\title{
Computed cell cycle and DNA histogram analyses in image cytometry in breast cancer
}

\author{
R Montironi, L Diamanti, A Santinelli, C Magi Galluzzi, M Scarpelli, I Giannulis, \\ F Mangili
}

Abstract

Aims-To analyse the cell cycle and DNA histogram components in data from DNA static cytometry and, in particular, to investigate the influence of the length of time the slides are exposed to the light of the cytophotometer in evaluating the $\mathbf{G}_{0} / \mathbf{G}_{1}$ peak.

Methods-DNA static cytometry was performed on 18 Feulgen stained imprints and six histological sections taken from six breast carcinomas. The total optical density values obtained were analysed using software commercially available as Multicycle. DNA flow cytometry was performed on the same cases. Results-The proportions of nuclei related to the cell cycle components from DNA static cytometric data, obtained from Feulgen stained cytological smears, were almost identical with those obtained from DNA flow cytometric data. Moreover, additional information was obtained from the DNA static cytometry frequency histogram and the proportions of nuclei below the diploid $G_{0} / G_{1}$ peak and above the $G_{2}$ phase. Discrepancies between DNA static cytometry and DNA flow cytometry were seen in the large coefficients of variation of the $G_{0} / G_{1}$ peaks obtained with the former method of analysis, even though a better correspondence was found when the exposure time of the slides to the light of the cytophometer was conspicuously shortened. The information obtained from histological sections seemed to be similar to that obtained from DNA flow cytometry when a single cell population was present; a single cell population was detected in two out of the three cases in which two distinct populations had been present in DNA flow cytometry.

Conclusions-The computer analysis of DNA static cytometric data obtained from Feulgen stained cytological specimens provides the type of information on the cell cycle which is usually obtainable only from DNA flow cytometry. Correspondence with the DNA data from histological sections, however, was poor.

(F Clin Pathol 1993;46:795-800)

At the Porto Meeting hold in September 1989, the officers of the Committee for Diagnostic Quantitative Pathology (formerly a Working Group of the European Society of Pathology) decided to create a subcommittee dealing with the standardisation of nuclear DNA content analysis. ${ }^{1}$ This subcommittee was entrusted with the plan of investigating the variations in DNA static cytometry, and with giving specific advice for an objective and reproducible analysis of the nuclear DNA. The nature and sources of variations in the successive steps of the DNA evaluation were investigated by exploring the influence of the methods of preparing the material and the analysis techniques in DNA static cytometry. The results have already been covered in previous papers. They show that general agreement and optimisation for cell preparation procedures, cytochemistry, and feature analysis, as well as data handling and interpretation, are essential to permit meaningful comparisons of DNA static cytometry results from different laboratories. ${ }^{23}$

Recently investigation has started into the specific recommendations useful for an objective and reproducible analysis of the nuclear DNA content. The topic currently under investigation is a feasibility study of cell cycle analysis in DNA static cytometry. Initially, manual and automatic (computer aided) methods were considered. ${ }^{45}$ Then it was decided to use an automatic method for cell cycle analysis whose software (Multicycle) was installed in the computer of our IBAS Kontron image analyser. Before our study was undertaken, it was shown that the computer aided determination of the $S$ phase fraction seems to be feasible in DNA static cytometry on Feulgen stained cytological material, even though large coefficients of variation for the $G_{0} / G_{1}$ peaks were obtained. ${ }^{67}$ This was seen as a serious problem, because large values preclude discrimination between two populations with a similar DNA content.

\section{Methods}

The study was performed on six cases of infiltrating ductal carcinoma of the female breast. These had already been collected for the purpose of evaluating the DNA index and the ploidy pattern in DNA flow cytometry. The fresh tumour tissue was divided into two parts with a scalpel. Eighteen imprints-three per case identified as imprint A, B, and Cwere obtained by touching the freshly cut surface with glass slides. These cytological preparations were air dried for 30 minutes at room temperature, then fixed in $10 \%$ buffered neutral formalin for 30 minutes, and 
washed in distilled water for 10 minutes. One part of the nodule was then fixed in $10 \%$ buffered neutral formalin for 12 to 18 hours, dehydrated in alcohol (50\%, 70\%, $90 \%$ twice, $100 \%$ twice), cleared in xylene (twice), and embedded in paraffin wax. The other part was used for DNA flow cytometry. In each case serial $5 \mu \mathrm{m}$ thick histological sections were cut from the paraffin wax block for morphological diagnosis, immunohistochemical staining, and DNA static cytometric analysis. The 18 imprints and six $5 \mu \mathrm{m}$ thick histological sections-one per case-were stained according to the standard Feulgen reaction procedure used in our institutes. ${ }^{23}$

DNA static cytometric analysis was performed using an IBAS image analyser (Kontron Elektronik, Eching/Munich, Germany) with the DNA Measurement Software Package (Release 2.0). Before measurements were made, the lamp was mechanically adjusted to obtain optimal light intensity and homogeneous illumination; measurements were started 15 minutes after switching on the system and lamp-when the densitometric values had stabilised. Glare was corrected for by subtracting $10 \%$ of the $100 \%$ transmission level measured in a background area without visible particles. One cytological preparation per case-that is, the six identified by the letter $\mathrm{A}$-was measured at an objective magnification of 100 times (oil immersion; numerical aperture 1.32); the remaining 12 imprints, identified by the letters $\mathrm{B}$ and $\mathrm{C}$, as well as the six histological sections were evaluated at an objective magnification of 40 times (dry; numerical aperture 0.75 ). In each slide preparation the total optical density of 1000 well preserved and cytologically identified neoplastic cells was obtained by adopting a vertical stratified selection method (filter $560 \mathrm{~nm}$ ). Both the microscope image of each nucleus and the corresponding contoured image on the monitor were checked by the observer. The objects were accepted for analysis on the condition that the contoured image was satisfactory on visual inspection. This procedure permitted the interactive measurement of about 150 nuclei per hour at an objective magnification of 100 times and of about 350 nuclei an hour at an objective magnification of 40 times. In a preliminary investigation the total optical density of the same 50 nuclei was first measured at an objective magnification of 40 and then 100 times. No significant differences were observed.

The total optical density values were recorded in the IBAS computer as a 256 channel histogram and analysed using software commercially available as Multicycle (version 2.12; Phoenix Flow Systems, San Diego, California, USA). The mathematical method of analysis, developed by Dean and Jett, ${ }^{5}$ uses Gaussian distributions for the calculation of the $G_{0} / G_{1}$ and $G_{2}$ curves, and a polynomial curve to calculate the $S$ phase. In a previous paper, ${ }^{7}$ we provided details of how this software can be applied to DNA static cytometric data. The following features were recorded: percentage of nuclei in $\mathrm{G}_{0} / \mathrm{G}_{1}$ (\%G1), percentage of nuclei in $S$ phase $(\% S)$, percentage of nuclei in $\mathrm{G}_{2}(\% \mathrm{G} 2)$, and the coefficient of variation (standard deviation divided by the peak mean multiplied by 100 ) of the $G_{0} / G_{1}$ peak (G1CV). The DNA index (DI) was calculated as the ratio of the mean channel value of the $G_{0} / G_{1}$ peak of the tumour cell population to that of the $G_{0} / G_{1}$ peak of 100 small malignant stromal lymphocytes (internal diploid reference) whose total optical density values were multiplied by a factor of 1.4 to compensate for the "proportionality error". ${ }^{7}$ When two distinct tumour cell populations were present on the frequency histogram, DI was the ratio of the second $G_{0} / G_{1}$ peak to the first $G_{0} / G_{1}$ peak. The proportions of nuclei on the histogram below the first $G_{0} / G_{1}$ peak $(\%<G 1)$ and above the $\mathrm{G}_{2}$ phase ( $\left.\%>\mathrm{G} 2\right)$ were also evaluated. $\%<\mathrm{G} 1$ and $\%>\mathrm{G} 2$ were calculated in relation to the number of nuclei measured for each case-1000 nuclei; $\% \mathrm{G} 1, \% \mathrm{~S}$, and $\% \mathrm{G} 2$ expressed the relative proportion of nuclei in the three phases of the cell cycle.

The DNA flow cytometric analysis was performed on fresh tumour tissue. The specimen was mechanically dissociated and then stained with propidium iodine. Axillary lymph node tissue (without secondary deposits) was used as a diploid reference. The nuclear suspensions were analysed on a FACScan flow cytometer (Becton Dickinson, Mountain View, California USA). A total count of at least 20000 pulses was measured for the DNA distribution, displayed, and recorded as a 256 channel histogram, \%G1, $\% \mathrm{~S}$, and \%G2, as well as the G1CV and DI, were evaluated using the DNA Cell-Cycle Analysis Software (Version C 5/87, Polynomial Model).

\section{Results}

The cases investigated were divided into two groups on the basis of the number of $G_{0} / G_{1}$ peaks present in DNA flow cytometry. One group contained three cases with one peakthat is, a single cell population (cases 1 to 3); the other group included the remaining three cases which were characterised by two peaks-that is, two cell populations (cases 4 to 6 ). The data are reported in tables 1 and 2 .

DNA STATIC CYTOMETRY IN IMPRINTS

For the cases in the group with a single cell population, the DNA flow cytometric analysis showed a histogram with a single $G_{0} / G_{1}$ peak containing most of the nuclei, accompanied by elements in the $\mathrm{G}_{2}-\mathrm{M}$ compartment and in the $S$ phase. As for the nine cytological preparations, the DNA static cytometric analysis, based on the Multicycle software, produced a frequency histogram similar to that obtained in DNA flow cytometry-that is, a $G_{0} / G_{1}$ peak with a recognisable $G_{2}$ compartment and an intermediate component corresponding to the $S$ phase (fig 1). For the cell cycle data, good correspondence between DNA flow cytometry and DNA static cytometry 
Table 1 Histogram and cell cycle data in three cases with one peak

\begin{tabular}{|c|c|c|c|c|c|c|c|}
\hline & \multicolumn{7}{|c|}{ Cell cycle data } \\
\hline & $\%<G 1^{*}$ & $\%$ of total & $\% G 1$ & $G 1 C V$ & $\% S$ & $\% G 2$ & $\%>G 2 t$ \\
\hline \multicolumn{8}{|l|}{ Case 1} \\
\hline Imprint A & $1.0 \%$ & $95 \cdot 2 \%$ & $73 \cdot 2 \%$ & 15.9 & $12.0 \%$ & $14 \cdot 8 \%$ & $3.8 \%$ \\
\hline Imprint $B$ & $0.6 \%$ & $98.4 \%$ & $79.4 \%$ & $11 \cdot 3$ & $14 \cdot 4 \%$ & $6 \cdot 2 \%$ & $1.0 \%$ \\
\hline Imprint $C$ & $0 \cdot 7 \%$ & $97 \cdot 2 \%$ & $73.5 \%$ & 9.7 & $16 \cdot 2 \%$ & $10.3 \%$ & $2 \cdot 1 \%$ \\
\hline Histology & $1.8 \%$ & $94.2 \%$ & $81.7 \%$ & $15 \cdot 3$ & $15.8 \%$ & $2.5 \%$ & $4.0 \%$ \\
\hline $\begin{array}{l}\text { DNA flow cytometry } \\
\text { Case } 2\end{array}$ & NAf & $100 \%$ & $81.0 \%$ & $4 \cdot 0$ & $12 \cdot 0 \%$ & $7.0 \%$ & $\mathrm{NA}$ \\
\hline \multicolumn{8}{|l|}{ DNA static cytometry } \\
\hline Imprint $A$ & $0.4 \%$ & $97 \cdot 3 \%$ & $75.9 \%$ & $13 \cdot 7$ & $21 \cdot 5 \%$ & $2 \cdot 6 \%$ & $2 \cdot 3 \%$ \\
\hline Imprint B & $0.8 \%$ & $97.6 \%$ & $91.2 \%$ & $7 \cdot 4$ & $3.7 \%$ & $5.1 \%$ & $1.6 \%$ \\
\hline Imprint C & $\begin{array}{l}0.7 \% \\
0.9 \%\end{array}$ & $97 \cdot 8 \%$ & $\begin{array}{l}84 \cdot 2 \% \\
78.6 \%\end{array}$ & $\begin{array}{r}9 \cdot 4 \\
18.4\end{array}$ & $\begin{array}{r}8.5 \% \\
15.3 \%\end{array}$ & $7 \cdot 3 \%$ & $1.5 \%$ \\
\hline DNA flow cytometry & NA & $100 \%$ & $\begin{array}{l}78.6 \% \\
68.0 \%\end{array}$ & $\begin{array}{r}18 \cdot 4 \\
4 \cdot 0\end{array}$ & $\begin{array}{l}15 \cdot 3 \% \\
25 \cdot 0 \%\end{array}$ & $\begin{array}{l}6 \cdot 1 \% \\
7 \cdot 0 \%\end{array}$ & $\begin{array}{l}5 \cdot 0 \% \\
\mathrm{NA}\end{array}$ \\
\hline \multicolumn{8}{|l|}{ DNA static cytometry } \\
\hline Imprint A & $0 \cdot 4 \%$ & $98 \cdot 1 \%$ & $85 \cdot 8 \%$ & $16 \cdot 0$ & $11 \cdot 8 \%$ & $2 \cdot 4 \%$ & $1.5 \%$ \\
\hline Imprint B & $0.5 \%$ & $98.3 \%$ & $92.9 \%$ & $10 \cdot 2$ & $\mathbf{4 \cdot 4} \%$ & $2 \cdot 7 \%$ & $1.2 \%$ \\
\hline Imprint $C$ & $1.0 \%$ & $98.1 \%$ & $95.0 \%$ & $10 \cdot 4$ & $3 \cdot 4 \%$ & $1.6 \%$ & $0.9 \%$ \\
\hline Histology & $0.8 \%$ & $97 \cdot 8 \%$ & $78.6 \%$ & $14 \cdot 0$ & $21 \cdot 4 \%$ & $0.0 \%$ & $1.4 \%$ \\
\hline DNA flow cytometry & $\mathbf{N A}$ & $100 \%$ & $84.0 \%$ & 4.4 & $11.0 \%$ & $5.0 \%$ & NA \\
\hline
\end{tabular}

$\star \%<G 1$ is the proportion of nuclei below the first $G_{0} / G_{1}$ peak, $\dagger \%>G 2$ is the proportion of nuclei in the region above the $G_{2}$ component. $¥$ NA stands for data not available.

with a DNA index of 1.0 was observed in both.

Three out of the six cases investigated were grouped together because the DNA flow cytometric analysis showed two distinct peaks, the first diploid and the second aneuploid (diploidy and aneuploidy refer to DNA diploidy and DNA aneuploidy and not to chromosomal aneuploidy). Unfortunately, the cell cycle had not been evaluated in these three cases at the time of the original DNA flow cytometric analysis, nor had the values of the computer files been stored for further analysis. The histogram pattern of the DNA static cytometry values analysed using the Multicycle software, however, was similar to that obtained with DNA flow cytometry (figs 2 and 3). The DI was almost identical in both types of DNA analysis. Discrepancy was observed in the G1CVs. In particular, when the static cytometry analysis time was longer than seven hours (as in the six A imprints), the static cytometric values were, in general, greater than 13 , reaching a maximum of $16 \cdot 3$ - that is, more than double those in flow cytometry, where the values available were lower than 5 . When the analysis time was shorter than three hours, however, the G1CVs in the 12 imprints B and C, intermediate between those observed in DNA static cytometry with seven hours of analysis and those obtained in DNA flow cytometry, were, in general, lower than 10, with a minimum of 6.5 . For the data relating to the histogram and cell cycle evaluation, the time of analysis only yielded small differences between imprints $A, B$, and $C$.

In all the 18 imprints a small percentage of nuclei (usually less than $1 \%$ ) was always present in the histogram region below the first $\mathrm{G}_{0} / \mathrm{G}_{1}$ peak, most being in that part of the region between half the mean channel value of the $G_{0} / G_{1}$ peak and the beginning of the $\mathrm{G}_{0} / \mathrm{G}_{1}$ curve. The proportion of nuclei above

Table 2 Histogram and cell cycle data in three cases with two peaks

\begin{tabular}{|c|c|c|c|c|c|c|c|c|c|c|c|}
\hline & \multirow[b]{3}{*}{$\%<G 1^{\star \star}$} & \multirow[b]{3}{*}{$\begin{array}{l}\% \text { of } \\
\text { total }\end{array}$} & \multicolumn{9}{|c|}{ Cell cycle data } \\
\hline & & & \multicolumn{2}{|l|}{ Diploid } & \multicolumn{4}{|c|}{ Aneuploid* } & \multirow[b]{2}{*}{$\% G 2$} & \multirow[b]{2}{*}{$D I$} & \multirow[b]{2}{*}{$\%>G 2 t$} \\
\hline & & & $\% G 1$ & GICV & $\begin{array}{l}\text { \% of } \\
\text { aneuploid }\end{array}$ & $\% G 1$ & $G 1 C V$ & $\% S$ & & & \\
\hline \multicolumn{12}{|l|}{$\begin{array}{l}\text { Case } 4 \\
\text { DNA static cytometry }\end{array}$} \\
\hline Imprint $A$ & $0.7 \%$ & $99 \cdot 0 \%$ & $39 \cdot 3 \%$ & $12 \cdot 3$ & $60 \cdot 7 \%$ & $63 \cdot 2 \%$ & $12 \cdot 3$ & $23 \cdot 3 \%$ & $13.5 \%$ & $1 \cdot 6$ & $0.3 \%$ \\
\hline Imprint B & $1.2 \%$ & $97 \cdot 8 \%$ & $38 \cdot 6 \%$ & $7 \cdot 8$ & $61 \cdot 4 \%$ & $59 \cdot 4 \%$ & $6 \cdot 5$ & $29 \cdot 8 \%$ & $10 \cdot 8 \%$ & 1.5 & $1.0 \%$ \\
\hline Imprint C & $1.0 \%$ & $97 \cdot 7 \%$ & $15 \cdot 3 \%$ & $9 \cdot 7$ & $84 \cdot 7 \%$ & $69 \cdot 6 \%$ & $9 \cdot 4$ & $19.0 \%$ & $11 \cdot 4 \%$ & 1.5 & $1.3 \%$ \\
\hline Histology & $1.2 \%$ & $96 \cdot 8 \%$ & $14 \cdot 4 \%$ & $12 \cdot 1$ & $85.6 \%$ & $49 \cdot 6 \%$ & $19 \cdot 6$ & $40.7 \%$ & $9 \cdot 7 \%$ & 1.6 & $2.0 \%$ \\
\hline $\begin{array}{l}\text { DNA flow cytometry } \\
\text { Case } 5\end{array}$ & NA & $100 \%$ & NA & $\mathrm{NA}$ & NA & NA & $\mathrm{NA}$ & NA & NA & 1.6 & $\mathrm{NA}$ \\
\hline \multicolumn{12}{|l|}{ DNA static cytometry } \\
\hline Imprint A & $1.0 \%$ & $96 \cdot 5 \%$ & $31 \cdot 7 \%$ & $14 \cdot 4$ & $68 \cdot 3 \%$ & $64 \cdot 4 \%$ & $13 \cdot 5$ & $19 \cdot 0 \%$ & $16 \cdot 6 \%$ & $1 \cdot 6$ & $2.5 \%$ \\
\hline Imprint B & $\begin{array}{l}1.2 \% \\
0.6 \%\end{array}$ & $\begin{array}{l}\mathbf{9 8 \cdot 4} \% \\
97 \cdot 1 \%\end{array}$ & $\begin{array}{l}17 \cdot 3 \% \\
23 \cdot 1 \%\end{array}$ & $\begin{array}{l}10 \cdot 8 \\
12 \cdot 9\end{array}$ & $\begin{array}{l}82 \cdot 7 \% \\
76.9 \%\end{array}$ & $61 \cdot 3 \%$ & $14 \cdot 7$ & $29 \cdot 4 \%$ & $9 \cdot 3 \%$ & 1.6 & $0.4 \%$ \\
\hline Histology & $1.5 \%$ & $\begin{array}{l}97.1 \% \\
97.2 \%\end{array}$ & $23 \cdot 1 \%$ & & $100 \%$ & $53.6 \%$ & $\begin{array}{l}12.7 \\
28.8\end{array}$ & $\begin{array}{l}24 \cdot 3 \% \\
42 \cdot 8 \%\end{array}$ & $\begin{array}{r}14 \cdot 0 \% \\
3.6 \%\end{array}$ & $1 \cdot 3$ & $\begin{array}{l}2.3 \% \\
1.3 \%\end{array}$ \\
\hline DNA flow cytometry & NA & $100 \%$ & NA & NA & NA & NA & $\mathrm{NA}$ & $\mathrm{NA}$ & $\mathrm{NA}$ & $1 \cdot 6$ & $\mathrm{NA}$ \\
\hline \multicolumn{12}{|c|}{$\begin{array}{l}\text { Case } 6 \\
\text { DNA static cytometry }\end{array}$} \\
\hline Imprint A & $1.0 \%$ & $98 \cdot 3 \%$ & $21.5 \%$ & $11 \cdot 20$ & $78 \cdot 5 \%$ & $69 \cdot 0 \%$ & $16 \cdot 3$ & $20 \cdot 5 \%$ & $10 \cdot 5 \%$ & $2 \cdot 4$ & $0.7 \%$ \\
\hline Imprint B & $0.9 \%$ & $97 \cdot 4 \%$ & $13 \cdot 0 \%$ & $9 \cdot 9$ & $87 \cdot 0 \%$ & $74 \cdot 1 \%$ & $10 \cdot 9$ & $16 \cdot 6 \%$ & $9 \cdot 3 \%$ & $2 \cdot 3$ & $1.7 \%$ \\
\hline Imprint C & $0.8 \%$ & $99 \cdot 2 \%$ & $15 \cdot 0 \%$ & $9 \cdot 6$ & $85 \cdot 0 \%$ & $75 \cdot 1 \%$ & $10 \cdot 2$ & $14 \cdot 6 \%$ & $10 \cdot 3 \%$ & $2 \cdot 3$ & $0.0 \%$ \\
\hline Histology & $4 \cdot 0 \%$ & $94 \cdot 4 \%$ & & & $100 \%$ & $71 \cdot 3 \%$ & $19 \cdot 5$ & $28 \cdot 7 \%$ & $0.0 \%$ & & $1.6 \%$ \\
\hline DNA flow cytometry & NA & $100 \%$ & NA & NA & NA & NA & NA & NA & NA & $2 \cdot 4$ & NA \\
\hline
\end{tabular}




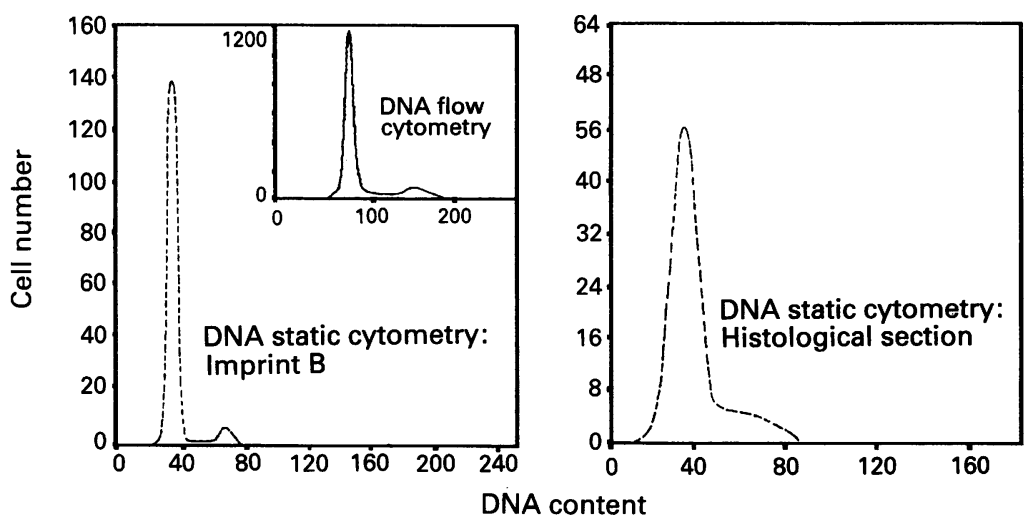

Figure 1 The DNA static cytometric analysis of imprint $B$ of case 2 produced a histogram similar to that obtained in DNA flow cytometry (see inset) -a $G_{0} / G_{1}$ peak with a recognisable $G_{2}$ peak and an intermediate component corresponding to the $S$ phase. The histogram obtained from the histological section in the same case reproduced that of the corresponding cytology.
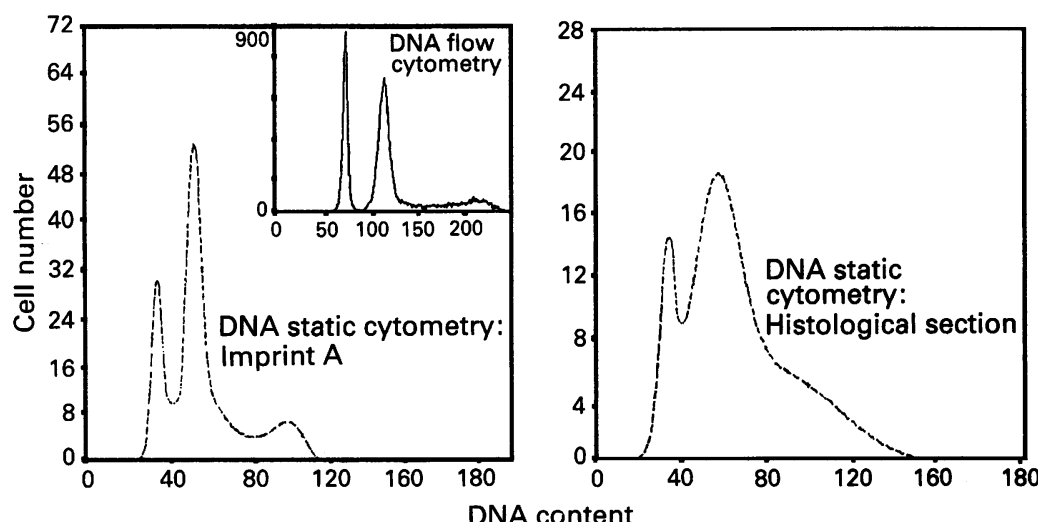

Figure 2 The pattern of the DNA static cytometric histogram of imprint $A$ of case 4 was almost identical with that obtained with the DNA flow cytometry (see inset) - two distinct peaks, the first diploid and the second aneuploid. The histogram obtained from the histological section in the same case showed two broad peaks positioned close together.

the $G_{2}$ phase (up to $3 \cdot 8 \%$ ) was greater than that below the $G_{0} / G_{1}$ peak.

\section{DNA STATIC CYTOMETRY IN HISTOLOGICAL SECTIONS}

For the three cases with a single cell population, the pattern of the frequency histogram and the values of the cell cycle were similar to those obtained in the imprints. The G1CVs,

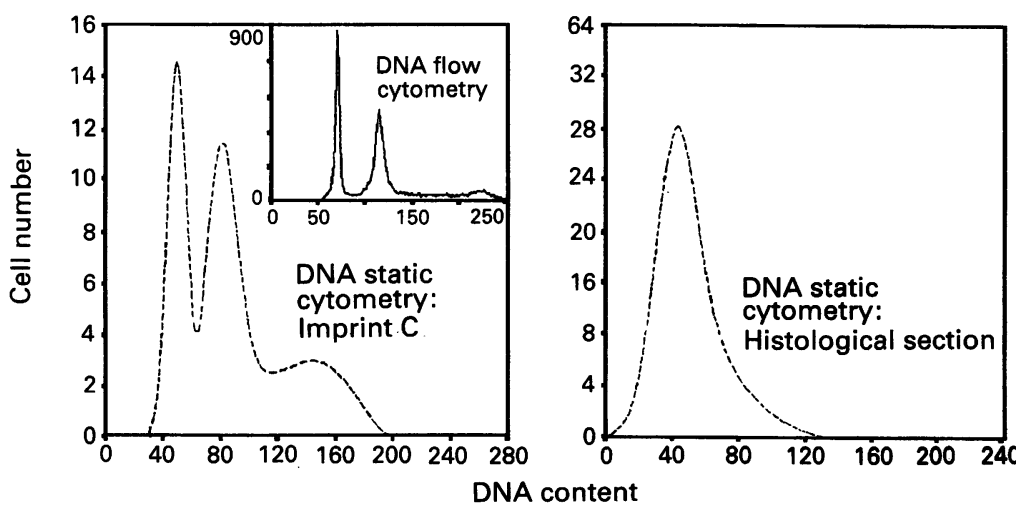

Figure 3 Two distinct peaks, the first diploid and the second aneuploid, were observed in $D N A$ flow cytometry and DNA static cytometry (imprint $C$ of case 5). The histogram obtained from the histological section in the same case showed only one peak, which appeared to be very broad. however, were as high as those obtained in the A imprints after seven hours of analysis. For the three cases with two distinct peaks, these were present in the histological section of only one case. In the other two, the CV of the only $G_{0} / G_{1}$ peak present in the histological section was as high as $19 \cdot 5$ and $28 \cdot 8$. The proportion of nuclei in the histogram region below the first $G_{0} / G_{1}$ peak and above the $G_{2}$ phase was greater than in the cytological preparations (figs 1,2 , and 3 ).

\section{Discussion}

It has recently been re-emphasised that some degree of discrepancy can exist between the information obtained from DNA static cytometry and DNA flow cytometry. ${ }^{8-14}$ Such discordance can, to some extent, be explained and minimised by optimising the procedures for cell preparation, cytochemistry, and feature analysis, including the measurement of an adequate number of nuclei, and adopting an appropriate selection method for the nuclei to be analysed. ${ }^{7}$ In a previous paper dealing with DNA static cytometry and related to the present study, we found that a sample size of at least 1000 nuclei can be regarded as adequate. Fewer nuclei-for example, 600-can still be sufficient for a case with a single cell cycle population; 200 seemed to be insufficient to obtain DNA static cytometric data similar to those from DNA flow cytometry. This is far greater than the sample size used by Elsheikh et $a l^{9}$ in their comparative DNA study of solid tumours by flow cytometric and image analyses: a minimum of 60 cells were analysed in each case (range 60 to 249 cells, mean 171). Like us, Smeulders and Dorst ${ }^{15}$ showed that the DNA histogram data obtained by measuring 1100 cells in density mode were almost identical with those obtained with more than 50000 nuclei analysed by flow cytometry in fluorescence mode. One could object that, when using a 256 channel histogram, the sample size:dimension ratio (the number of nuclei measured in relation to the number of intervals or channels on the abscissa of the histogram) is too low to obtain significant results and too close to the lowest theoretical limit of a ratio of $3: 1.1617$ When the data were also plotted with 30 to 50 intervals or channels with a ratio of 20 to 30 , however, there were no substantial differences with the 256 channel representation.

Another cause of the discrepancy between DNA static cytometry and DNA flow cytometry could be the selection method. ${ }^{18}$ The vertical stratified selection method was preferred to that called "at convenience" (measuring objects at will while scanning through the slide), because the former allows the user to measure 1000 sequential nuclei, mimicking the conditions of flow cytometry, if lymphocytes, pyknotic (apoptotic), and poorly preserved nuclei are excluded from the analysis. ${ }^{67}$ In contrast, these objects are usually evaluated in DNA flow cytometry. If their proportion in the cell suspension for DNA flow cytometry 
is not too high, however, as in the cases we included in the study, the DNA histogram representation of the population under investigation is not seriously affected.

Several ways to evaluate DNA static cytometry data have been devised, the most popular being the histogram classification by Auer et al. ${ }^{8}$ This, however, is subjective. Boecking and his group proposed a well known mathematical approach to the evaluation of the DNA data. ${ }^{19}$ The two main problems with most DNA related features proposed are, firstly, that they are calculated in relation to the diploid reference, usually lymphocytes. This shows some degree of proportionality error when optical density is evaluated in Feulgen stain; and, secondly, that there is no agreement on the thresholds for the ploidy regions. ${ }^{32021}$ At the same time the approach to evaluating the DNA static cytometry data adopted in most published studies seems to be quite different from that adopted in flow cytometry, a technique in which the features are directly related to the cell cycle. ${ }^{2}$ Our basic idea has been that the approach to analysing the DNA static cytometry features should basically be identical to that in flow cytometry and that the language used in both techniques should be the same. Based on the results obtained in the present study as well as in previous papers ${ }^{167}$ this would seem to be feasible. Therefore, the comparison between the two techniques has been based on common ground. When this approach was first adopted, one of the main problems was that the CVs of the $G_{0} / G_{1}$ peaks obtained in DNA static cytometry were more than twice as high as those in DNA flow cytometry- $\sim 15 v<5$, respectively, thus precluding any possibility of detecting peaks which in DNA static cytometry were very close. A considerable reduction in the CVs of the $G_{0} / G_{1}$ peaks has been achieved by reducing the analysis time from more than seven hours to less than three. In fact, the CVs then ranged from 6.5 to $\sim 10$. These values are quite similar to those obtained by Smeulders and Dorst, ${ }^{15}$ who used a very fast image analyser. The reduction in CVs could be linked to the degree of bleaching of Feulgen stained material, depending on the light exposure time, with consequent influence on the optical density values. ${ }^{22}$ We have already reported that exposure to sunlight is responsible for fading Feulgen stained slides and for very large CVs. ${ }^{1}$

We do not have any direct evidence that the nuclei, which in DNA static cytometry appear in $S$ and $G_{2}$ phases, are all related to the synthetic phase of the cell cycle. In an earlier study, however, the percentage of nuclei in the $S$ region determined in DNA static cytometry and DNA flow cytometry was similar to that of the darkest proliferating cell nuclear antigen-stained nuclei, which correspond to nuclei in the synthetic phase. ${ }^{6}$ Recently, Kouvidou et $a l^{23}$ presented a more elaborate approach, using a computed system to relocate the cells on the slide. They showed that the nuclei corresponding to the
$S$ phase on the histogram were also positive for proliferation markers specific for this part of the cell cycle.

In all the cases we evaluated there was always a certain percentage of nuclei in the region below the $G_{0} / G_{1}$ peak. This is a poorly investigated region which might have prognostic importance but which cannot be fully investigated in DNA flow cytometry because the optical resolution is zero, so the objects analysed can not be seen by the observer. As we measured only well preserved nuclei, those contained in this region may represent elements with a reduced DNA content. This could be due to an unequal distribution of chromosomes at the time of nuclear division-cells whose sisters are roughly triploid. Alternatively, the reduced DNA content could be related to the presence of acid-labile DNA removed at the time of acid hydrolysis. This was well investigated by Sincock ${ }^{24}$ in cases of cervical intraepithelial neoplasia. Interestingly, we observed that apoptotic nuclei have a DNA content lower than that of diploid nuclei and occupy the histogram region below the diploid (unpublished data). This observation is similar to that made by Telford et $a l^{25}$ who investigated the region below the $G_{0} / G_{1}$ phase, termed the $A_{0}$ region, using flow cytometry. They showed that the appearance of the $A_{0}$ region may be the consequence of extensive changes in chromatin structure. Arends $e t a l^{26}$ investigated this further and observed that there is partial loss of DNA content in apoptotic nuclei after chromatin digestion with hydrochloric acid. This finding agrees with Sincock's observations that the dysplastic and neoplastic nuclei contain a certain percentage of DNA that is rapidly removed after acid hydrolysis. ${ }^{24}$ In the light of the work by Telford $e t a l^{25}$ and Arends et $a l^{26}$ the nuclei we observed in the region below the $G_{0} / G_{1}$ peak may be related to the apoptotic phenomenon and in some way considered a feature of tumour regression.

The percentage of nuclei above the $G_{2}$ phase corresponds to the 5c Exceeding Rate proposed by Boecking et al. ${ }^{19}$ Because the latter was not calculated in our study, we do not have any direct evidence of the degree of correspondence in terms of values between the two features. $\%>\mathrm{G} 2$, however, is easy to identify because its lower limit is clearly identifiable as the upper limit of the Gaussian curve superimposed on $\mathrm{G}_{2}$, and is linked neither to the thresholds of the $4 c$ or $5 c$ component, nor to the diploid reference.

In our study some correspondence was observed between DNA flow cytometry and DNA static cytometry in histology in imprints with DNA static cytometry in those cases in which a single cell population was shown. In contrast, correspondence was poor when two populations were present, due to the fact that the nuclei are cut. Therefore, the loss of one part of the nucleus influences the distribution of the nuclei in the different regions of the cell cycle and of the histogram. ${ }^{14}$ This means that the data obtained from sections can not be considered as reliable as those from 
cytological preparations. This result also strengthens the widely held idea that nuclear DNA content evaluation in histology should be avoided unless to identify specific cells to be measured. ${ }^{27}$

In conclusion, the information obtained with DNA static cytometry in cytological preparations can at least be considered equivalent to that from DNA flow cytometry. The former could be considered preferable because it can simultaneously quantify several additional features related to the nucleus (such as chromatin pattern) and to the cytoplasm (such as size or type of contents). Moreover, an experienced histo- or cytopathologist can use the visual acumen to identify and measure specific cell populations. The analysis time in DNA static cytometry however, has to be shortened further and kept within a more reasonable period, while allowing the examiner to continue to retain a precise idea of what the instrument is measuring.

1 Montironi R, Diamanti L, Giannulis I, et al. Computeraided cell cycle analysis in DNA static cytometry: the early methodological approach was discouraging! Alpe Adria fournal of Medicine 1992;XLVII:281-92.

2 Montironi R, Diamanti L, Magi Galluzzi C, Giannulis I Optimization of DNA static cytometry. Arquivos de Patologia (Portugal) 1992;XXIV:15-35.

3 Montironi R, Scarpelli M, Santinelli A, Valli M, Whimster WF. DNA static cytophotometry in tumour pathology. Standardization of the procedure together with our Standardization of the procedure together with our joint seminar on medical informatics and bioengineering. joint seminar on medical informatics and bioeng

4 Baisch H, Gohde W, Linder WA. Analysis of PCP-data to determine the fractions of cells in various phases of cellcycle. Radiat Environ Biophys 1975;12:31-9.

5 Dean PN, Jett JH. Mathematical analysis of DNA distributions derived from flow microfluorimetry. $\mathcal{F}$ Cell Bio 1974;60:523-7.

6 Montironi R, Diamanti L, Magi Galluzzi C, Mangili F, Cantaboni A. S-phase fraction analysis in DNA static cytometry in breast cancer. Comparison with proliferating cell nuclear antigen (PCNA). Acta Stereol 1992; ing cell nucl

7 Montironi R, Diamanti L, Santinelli A, Scarpelli M. Sphase fraction determination in DNA static cytometry in breast cancer: a methodologic study on cytol

8 Auer GU, Askensten U, Erhardt K, Fallenius A Zetterberg A. Comparison between slide and flow cytophotometric DNA measurements in breast tumors.
Analyt Quant Cytol Histol 1987;9:138-46.

9 Elsheikn TM, Silverman JF, McCool JW, Riley RS Comparative DNA analysis of solid tumors by flow cytometric and image analyses of touch imprints and flow cell suspensions. Am 7 Clin Pathol 1992;98: 296-304.

10 Felman $\mathrm{P}$, French $\mathrm{M}$, Souchier $\mathrm{C}$, et al. Comparison between image and flow DNA cytometry in nonHodgkin's lymphomas. Path Res Pract 1989;185: 709-14.

11 Lee AKC, Dugan J, Hamilton WM, et al. Quantitative DNA analysis in breast carcinomas: a comparison between image analysis and flow cytometry. Mod Pathol 1991;4:178-82.

12 Robinson RA. Defining the limits of DNA cytometry. Am f Clin Pathol 1992;198:275-7.

13 Schneller J, Eppich E, Greenebaum E, et al. Flow cytometry and Feulgen cytophotometry in evaluation of effusions. Cancer 1987;59:103-13.

14 Koss LG. Image cytophotometry and flow cytometry. In: Coon JS, Weinstein RS, eds. Diagnostic flow cytometry. Coon JS, Weinstein RS, eds. Diagnostic flow

15 Smeulders AWM, Dorst L. An introduction to image processing. In: Baak JPA, ed. Manual of quantitative pathology in cancer diagnosis and prognosis. Berlin: pringer-Verlag, 1991;77-104.

16 Bartels PH, Weber JE, Bibbo M. Ploidy pattern analysis. Statistical considerations. Analyt Ouant Cytol Histol 1985;7:126-30.

17 Weber JE, Baldessarri BA, Bartels PH. Test statistics for detecting aneuploidy and hyperdiploidy. Analyt Quant Cytol Histol 1985;7:131-9.

18 van Diest PJ, Smeulders AWM, Thunnissen FBJM, Baak JPA. Cytomorphometry. A methodologic study of JPA. Cytomorphometry. A methodologic study of preparation techniques, selection methods and
size. Analyt Ouant Cytol Histol 1989;11:225-31.

19 Boecking A, Adler CP, Common HH, et al. Algorithm for Boecking A, Adler CP, Common $\mathrm{HH}$, et al. Algorithm for
DNA-cytophotometric diagnosis and grading of malignancy. Analyt Quant Cytol 1984;6:1-8.

20 Becker RL, Mikel UV. Interrelation of formalin fixation, chromatin compactness and DNA values as measured by flow and image cytometry. Analyt Quant Cytol Histol 1990;12:333-41.

21 Schulte EKW. Standardization of Feulgen reaction for absorption DNA image cytometry: a review. Analyt Cell Pathol 1991:3:167-82.

22 Kasten FH, Kiefer G, Sandritter W. Bleaching of Feulgen stained nuclei and alteration of absorption curve after continuous exposure to visible light in a cytophotomecontinuous exposure to visible light

23 Kouvidou H, Falkmer UG, Ahrens O, Hoog A, Falkmer S. A stepwise relocation technique for selective mage-cytometric DNA-analysis of neoplastic cells in the S phase. In: GS Delides, ed. Proceedings of the 7th international symposium on diagnostic quantitative pathology. Heraklion University Press, Crete, 1992:63.

24 Sincock AM. Semi-automated diagnosis of cervical intraepithelial neoplasia grade 2 by the measurement of acid labile DNA in cytologically normal nuclei. Cancer 1986; 58:83-6.

25 Telford WG King LE, Fraker PI. Comparative evaluation of several DNA binding dyes in the detection of apoptoof several DNA binding dyes in the detection of apoptosis-associated chromatin degra

26 Arends MJ, Morris RG, Wyllie AH. Apoptosis. The role of the endonuclease. Am $\mathcal{F}$ Pathol 1990;136:593-608.

27 Uyterlinde AM, Smeulders AWM, Baak JPA. DNA measurement errors with a scanning microdensitometer in cytologic and histologic samples of breast cancers. Analyt Quant Cytol Histol 1991;13:115-22. 